(2) Open Access Full Text Article

\title{
Accumulation of p62 is associated with poor prognosis in patients with triple-negative breast cancer
}

This article was published in the following Dove Press journal:

OncoTargets and Therapy

18 July 2013

Number of times this article has been viewed

\author{
Rong-Zhen Luo ${ }^{1,2, *}$ \\ Zhong-Yu Yuan ${ }^{1,3, *}$ \\ Mei $\mathrm{Li}^{1,2}$ \\ Shao-Yan $X^{1,2}$ \\ Jia $\mathrm{Fu}^{1,2}$ \\ Jiehua $\mathrm{He}^{1,2}$
}

'State Key Laboratory of Oncology in South China, ${ }^{2}$ Department of

Pathology, ${ }^{3}$ Department of Medical

Oncology, Sun Yat-Sen University

Cancer Center, Guangzhou, People's

Republic of China

*These authors contributed equally to this work
Correspondence: Jiehua $\mathrm{He}$ Department of Pathology, Sun Yat-Sen University Cancer Center, 65I Dongfeng East Road, Guangzhou 510060, People's Republic of China Tel +862087343622 Fax +86 2087343539

Email hejh@sysucc.org.cn
Background: Triple-negative breast cancer (TNBC) is associated with poor prognosis. There is an urgent need for elucidation of novel targets for TNBC therapy and to improve the prognosis of patients. The aim of this study was to evaluate the prognostic value of p62 expression in TNBC.

Methods and results: Expression of p62 in tissue microarray was evaluated by immunohistochemistry in 163 patients with TNBC. The prognostic value of $\mathrm{p} 62$ expression was assessed by a Cox regression model adjusted for clinical characteristics. Overexpression of p62 was observed in 51 (31.3\%) of 163 TNBC, and significantly correlated with advanced stage and a higher proportion of positive lymph nodes and lymphovascular invasion. A significant correlation was found between p62 expression and disease-free survival and overall survival. Accordingly, the 10-year distant metastasis-free survival for p62-overexpression and p62-underexpression patients were $58.9 \%$ and $92.5 \%$, respectively $(P<0.0001)$. Multivariate analysis indicated that p62-negative was a significant independent prognostic factor of disease-free survival $(P=0.017)$, but not for overall survival $(P=0.845)$ in all patients.

Conclusion: Our results suggest that overexpression of p62 in TNBC is associated with a higher risk of distant metastases. This finding could open new avenues for the development of novel therapy strategies for TNBC.

Keywords: triple-negative breast cancer, p62, prognosis, tissue microarrays

\section{Introduction}

Triple-negative breast cancers (TNBCs) are characterized by the lack of expression of estrogen receptor (ER), progesterone receptor (PR), and human epidermal growthfactor receptor 2 (HER2/neu). TNBC accounts for about 15\%-20\% of all breast cancers. ${ }^{1-4}$ It is associated with poor overall prognosis and high probability of distant metastases, especially lung and brain metastases. As metastatic disease is incurable, accurate prognosticators and more efficacious treatments are needed. The proclivity of breast cancer metastasis to particular organs may be mediated by specific genes. ${ }^{5-7}$

Also known as sequestosome 1, p62 has been characterized as an immediate early response gene, which has an important function in promoting survival signals, including proliferation, differentiation, and induction of antiapoptotic genes. ${ }^{8,9}$ As a multifunctional protein, abnormal expression of p62 has been documented in various cancers, including breast cancer, ${ }^{10}$ and the degree of p62 expression was significantly correlated with the formation of distant metastases. ${ }^{11}$ Thus, we hypothesized that p62 overexpression would be associated with TNBC exhibiting aggressive clinical behavior, such as being prone to distant metastases. 
In the current study, we detected expression of p62 protein in a larger sample size of TNBC tissue specimens for the association of p62 expression with clinicopathological features, disease relapse, and prognosis of the patients. Our data demonstrated that overexpression of $\mathrm{p} 62$ protein was associated with increasing risk of TNBC distant metastasis and poor survival of the patients.

\section{Materials and methods}

\section{Patients and tissue microarray}

This study comprised 163 female patients with TNBC diagnosed without any evidence of distant metastasis at the time of surgery between January 2000 and December 2008 at Sun Yat-Sen University Cancer Center. The cases selected were based on distinctive pathologic diagnosis of invasive breast cancer, availability of complete medical records and follow-up status, and lack of ER, PR, and HER2 expression. All patients were staged according to the American Joint Committee on Cancer (AJCC) TNM staging system for breast cancer (seventh edition).

In this study, paraffin-embedded pathologic specimens were retrieved from the archives of the Department of Pathology of Sun Yat-Sen University Cancer Center. Tissue microarrays were constructed as described previously. ${ }^{12}$ Each sample was arrayed in triplicate to minimize tissue loss and to overcome tumor heterogeneity. The Institute Research Medical Ethics Committee of Sun Yat-Sen University granted approval for this study. All sample donors gave written informed consent.

\section{Immunohistochemistry}

Tissue-microarray sections were immunohistochemically stained for p62. Briefly, tissue-microarray slides generated from the paraffin-embedded tissue blocks were deparaffinized and rehydrated for 5 minutes. After microwave pretreatment in citrate buffer $(\mathrm{pH}$ 6.0) for antigen retrieval, the slides were immersed in $0.3 \%(\mathrm{v} / \mathrm{v})$ hydrogen peroxide for 20 minutes to block endogenous peroxidase activity. The slides were then washed and incubated overnight at $4{ }^{\circ} \mathrm{C}$ with primary antibodies against p62 (mouse monoclonal antibody, clone D-3, Santa Cruz, dilution 1:100). After a second incubation with biotinylated antigoat antibodies, the slides were incubated with peroxidase-labeled streptavidin. The reaction products were visualized by immersing the slides in diaminobenzidine tetrachloride and counterstaining with Harris hematoxylin.

Immunohistochemical staining for p62 was evaluated according to intensity and proportion. The intensity score was determined as 0 (no staining), 1 (weak staining), 2 (moderate staining), and 3 (strong staining). The proportion score was determined as 1 ( $<30 \%$ of tumor cells) or 2 ( $\geq 30 \%$ of tumor cells). The intensity score and proportion score were multiplied together for a total score. Total scores were as follows: 0-1 (negative) and 2-6 (positive). All slides were evaluated independently by an investigator without knowledge of the identity of the patient or clinical outcome.

\section{Statistical analysis}

Clinicopathologic parameters were assessed between two subgroups by the chi-squared test. Cumulative survival probabilities were calculated through the Kaplan-Meier method. Survival rates were compared by log-rank test. Multivariate analyses were performed by the Cox regression model. Subsequently, variables with traditional prognostic factors, such as age at diagnosis, tumor size, lymph-node involvement, pathologic stage, and lymphovascular invasion were included in the multivariate analysis with enter model. All statistical tests were two-tailed, and $P<0.05$ was considered significant. All statistical analyses were performed using SPSS 17.0 (IBM, Armonk, NY, USA).

Disease-free survival (DFS) was defined as the interval from the date of operation to the date of first recurrence. Overall survival (OS) was calculated as the period from the date of diagnosis to the date of death. Locoregional relapse-free survival was defined as the interval from the first treatment for breast cancer to the first locoregional relapse. Distant metastasis-free survival was calculated as the period from the date of diagnosis to the date of distant metastasis or contralateral breast cancer. Locoregional relapse was defined as recurrence either in the treated breast or in the ipsilateral lymph node-bearing area (axillary, internal mammary, supraclavicular node).

\section{Results}

\section{p62 Protein expression in TNBC tissues and its association with clinicopathologic features}

A total of 163 paraffin-embedded archived TNBC tissues were subjected to immunohistochemical staining to quantify the expression of p62 protein. Representative images of p62 expression are shown in Figure 1. Using the median p62 staining score in TNBC as a cutoff value, high expression of p62 protein was detected in 51 (31.3\%) of the 163 cases, and low expression was detected in 112 (68.7\%). The association of p62 expression with various clinicopathological parameters is listed in Table 1. Compared with TNBC 
A

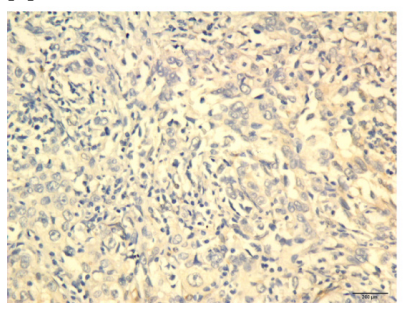

B

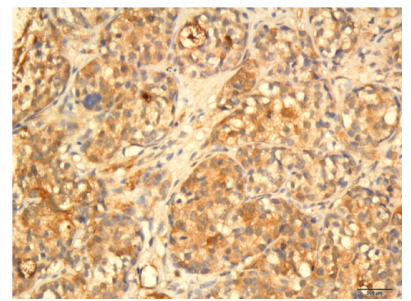

Figure I Representative immunohistochemical staining results for p62 (200x). (A) p62-negative; (B) p62-positive.

patients with low p62 expression, patients with high p62 expression had advanced AJCC stage and a higher proportion of positive lymph nodes and lymphovascular invasion.

\section{Survival}

As of December 2011, the median follow-up time was 112 months (range 15-145 months). Of 163 patients, 47 relapsed and 40 died. The 10-year DFS and OS of all patients were $70.7 \%$ and $75.8 \%$, respectively. When the patients were stratified in terms of p62 expression status, the 10-year DFS for low p62-expression and high p62-expression patients were $78.2 \%$ and $54.6 \%$, respectively $(P=0.002)$. OS for low p62-expression and high p62-expression patients was $81.7 \%$ and $62.7 \%$, respectively $(P=0.003)$. Accordingly, high p62-expression patients had a significantly higher risk of distant metastases than those with low p62 expression, and the 10-year distant metastasis-free survival for high p62-expression and low p62-expression patients was 58.9\% and $92.5 \%$, respectively $(P<0.0001)$. Locoregional relapsefree survival was no significantly different between high $\mathrm{p} 62$ expression and low p62-expression patients $(76.6 \%$ versus $81.2 \%, P=0.439$ ) (Figure 2A-D).

\section{Multivariate analysis}

Age at diagnosis, positive lymph nodes, higher stage, higher histological grade, present lymphovascular invasion, and p62 protein overexpression were significantly associated with reduced DFS and OS in univariate analysis (Tables 2 and 3). In the multivariate analysis, age at diagnosis, positive lymph nodes, and higher histological grade remained independent prognostic factors for shorter DFS and OS. However, p62 expression was a significant independent prognostic factor of DFS ( $P=0.017)$, though not for OS $(P=0.845)$ in all patients (Tables 2 and 3 ).

\section{Discussion}

It is well known that TNBC has a high mitotic index, high Ki67 expression, and a higher probability of distant metastases. ${ }^{13,14}$ Recent studies demonstrated that $\mathrm{p} 62$, as a multifunctional protein, is a central regulator of proliferation and metastases due to its abilities to modulate (and be a substrate of) autophagy, and to ensure a timely transit of cells

Table I Associations between p62 protein expression and clinicopathologic parameters*

\begin{tabular}{|c|c|c|c|c|}
\hline \multirow[t]{2}{*}{ Variable } & \multirow{2}{*}{$\begin{array}{l}\text { Total } \\
\text { population (\%) }\end{array}$} & \multicolumn{2}{|l|}{ p62 } & \multirow[t]{2}{*}{$P$-value } \\
\hline & & Underexpression, n (\%) & Overexpression, n (\%) & \\
\hline Total & 163 & I I 2 (68.7) & $51(31.3)$ & - \\
\hline Median age, years (range) & $47(22-79)$ & 47 (22-79) & $46(27-67)$ & 0.333 (Mann-Whitney) \\
\hline Age, n (\%) & & & & 0.420 \\
\hline$\leq 35$ & $37(22.7)$ & $23(20.5)$ & $14(27.5)$ & \\
\hline$>35$ & $126(77.3)$ & $89(79.5)$ & $37(72.5)$ & \\
\hline Tumor size, n (\%) & & & & 0.332 \\
\hline$\leq 2 \mathrm{~cm}$ & $4 \mathrm{I}(25.2)$ & 31 (27.7) & $10(19.6)$ & \\
\hline$>2 \mathrm{~cm}$ & $122(74.8)$ & $81(72.3)$ & $41(80.4)$ & \\
\hline Lymph-node status, n (\%) & & & & $<0.0001$ \\
\hline Negative & $90(55.2)$ & 79 (70.5) & II (2I.6) & \\
\hline Positive & $73(44.8)$ & $33(29.5)$ & $40(78.4)$ & \\
\hline AJCC stage, n (\%) & & & & $<0.0001$ \\
\hline $\mathrm{I} / \mathrm{II}$ & I2I (74.2) & $104(92.9)$ & $17(33.3)$ & \\
\hline III & $42(25.8)$ & $8(7.1)$ & $34(66.7)$ & \\
\hline Histological grade, n (\%) & & & & 1.000 \\
\hline I & $17(10.4)$ & $12(10.7)$ & $5(13.7)$ & \\
\hline II/III & $146(89.6)$ & $100(89.3)$ & $46(86.3)$ & \\
\hline Lymphovascular invasion, n (\%) & & & & $<0.000 \mathrm{I}$ \\
\hline Yes & $31(19.0)$ & $6(5.4)$ & $25(49.0)$ & \\
\hline No & $132(81.0)$ & $106(94.6)$ & $26(5 I .0)$ & \\
\hline
\end{tabular}

Note: $* \chi^{2}$ test.

Abbreviation: AJCC, American Joint Committee on Cancer. 

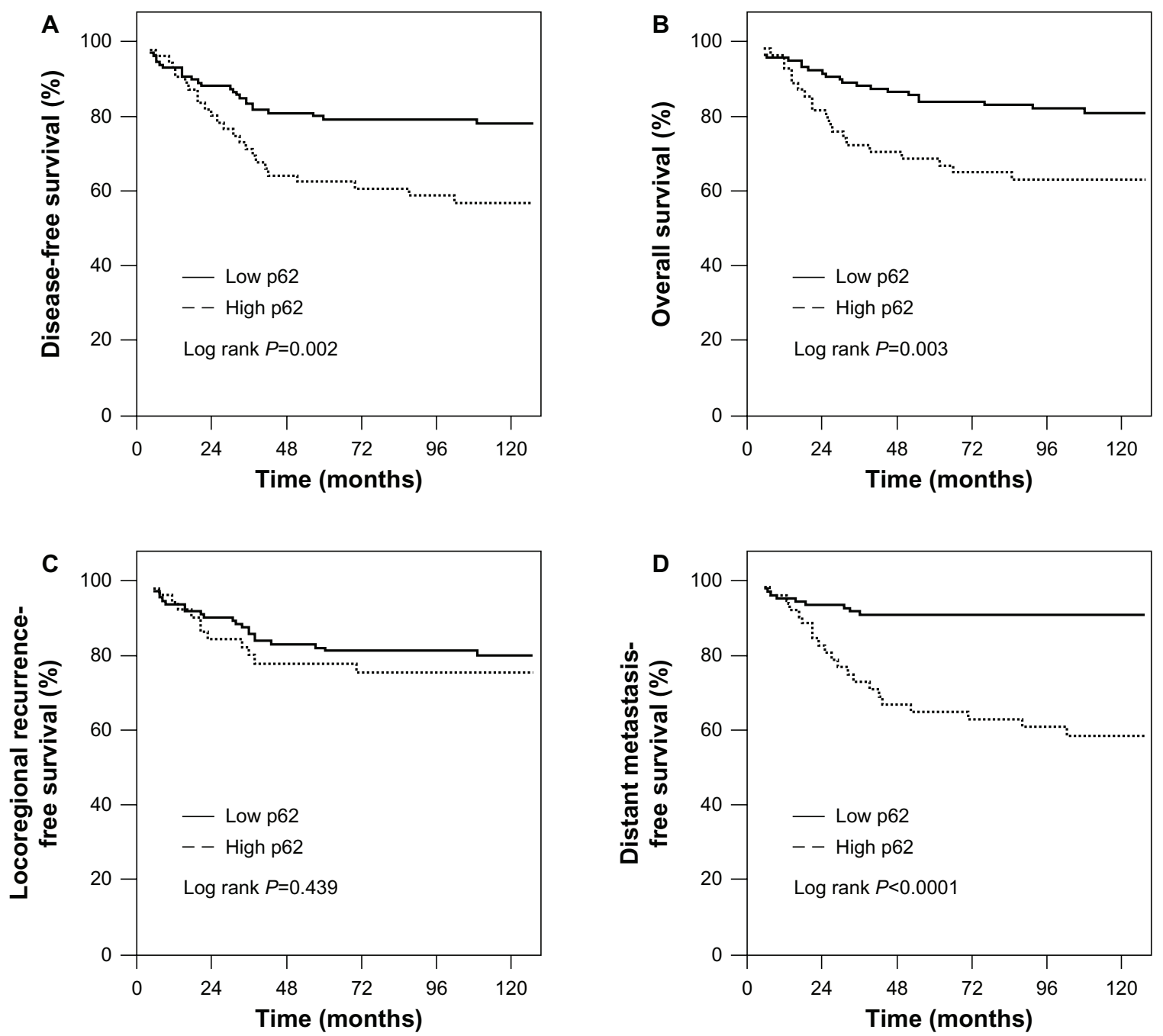

Figure 2 Association of p62 expression with poor prognosis of TNBC (triple-negative breast cancer) patient. (A) Disease-free survival, (B) overall survival, (C) locoregional relapse-free survival, and (D) distant metastasis-free survival according to the level of p62 protein expression.

through mitosis. ${ }^{15}$ Also, p62 may control oxygen consumption by regulating the activity of the extracellular signal-regulated kinase pathway, ${ }^{16}$ which is very important for rapidly growing TNBC cells. Therefore, p62 could be explored as a potential therapeutic target in cancer metastasis. ${ }^{15}$
No studies to date have linked p62 protein expression with TNBC clinical outcome. Here, we demonstrate for the first time that $\mathrm{p} 62$ protein is overexpressed in $31.3 \%$ of TNBC cases, which was higher than the proportion reported by Rolland et al, where $20.3 \%$ of p62 overexpression

Table 2 Univariate and multivariate analysis of disease-free survival in 163 patients with triple-negative breast cancer

\begin{tabular}{|c|c|c|c|c|c|c|}
\hline \multirow[t]{2}{*}{ Variables } & \multicolumn{3}{|c|}{ Univariate } & \multicolumn{3}{|c|}{ Multivariate } \\
\hline & HR & $95 \% \mathrm{Cl}$ & $P$-value & HR & $95 \% \mathrm{Cl}$ & $P$-value \\
\hline Age, years ( $\leq 35$ vs $>35$ ) & 0.45 & $0.25-0.81$ & 0.008 & 0.53 & $0.29-0.98$ & 0.041 \\
\hline Tumor size, $\mathrm{cm}(\leq 2$ vs $>2)$ & 1.54 & $0.74-3.18$ & 0.247 & 1.13 & $0.52-2.44$ & 0.759 \\
\hline Node status (negative vs positive) & 4.99 & $2.54-9.83$ & $<0.0001$ & 3.85 & $1.54-9.63$ & 0.004 \\
\hline Stage (I/II vs III) & 2.18 & $1.64-2.92$ & $<0.0001$ & 2.32 & $0.83-6.43$ & 0.107 \\
\hline Histological grade (I/II vs III) & 3.36 & $1.33-8.49$ & 0.010 & 0.28 & $0.10-0.74$ & 0.011 \\
\hline Lymphovascular invasion (no vs yes) & 4.95 & $2.77-8.12$ & $<0.0001$ & 1.21 & $0.5 \mathrm{I}-2.90$ & 0.668 \\
\hline p62 Expression (low vs high ) & 2.35 & $1.33-4.17$ & 0.003 & 1.78 & I.39-3.57 & 0.017 \\
\hline
\end{tabular}

Note: $\mathrm{HRs}$ and $95 \% \mathrm{Cls}$ were calculated using Cox regression analysis.

Abbreviations: $\mathrm{HR}$, hazard ratio; $\mathrm{Cl}$, confidence interval; vs, versus. 
Table 3 Univariate and multivariate analysis of overall survival in 163 patients with triple-negative breast cancer

\begin{tabular}{|c|c|c|c|c|c|c|}
\hline \multirow[t]{2}{*}{ Variables } & \multicolumn{3}{|c|}{ Univariate } & \multicolumn{3}{|c|}{ Multivariate } \\
\hline & HR & $95 \% \mathrm{Cl}$ & $P$-value & HR & $95 \% \mathrm{Cl}$ & $P$-value \\
\hline Age, years ( $\leq 35$ vs $>35)$ & 0.38 & $0.20-0.72$ & 0.003 & 0.43 & $0.23-0.82$ & 0.010 \\
\hline Tumor size, $\mathrm{cm}(\leq 2$ vs $>2)$ & 1.21 & $0.57-2.53$ & 0.621 & 0.83 & $0.37-1.85$ & 0.647 \\
\hline Node status (negative vs positive) & 5.09 & $2.42-10.70$ & $<0.0001$ & 4.01 & $1.43-11.25$ & 0.008 \\
\hline Stage (I/II vs III) & 2.21 & $1.62-3.03$ & $<0.0001$ & 2.28 & $0.79-6.59$ & 0.130 \\
\hline Histological grade (I vs II/III) & 2.71 & $1.06-6.92$ & 0.037 & 0.22 & $0.08-0.63$ & 0.004 \\
\hline Lymphovascular invasion (no vs yes) & 2.48 & I.42-4.39 & 0.003 & 1.20 & $0.48-2.99$ & 0.698 \\
\hline p62 Expression (low vs high) & 2.49 & $1.34-4.63$ & 0.004 & 0.93 & $0.45-1.91$ & 0.845 \\
\hline
\end{tabular}

Note: $\mathrm{HRs}$ and $95 \% \mathrm{Cls}$ were calculated using Cox regression analysis.

Abbreviations: $\mathrm{HR}$, hazard ratio; $\mathrm{Cl}$, confidence interval; vs, versus.

was observed in unselective breast cancer. ${ }^{11}$ In contrast, Choi et al reported that $\mathrm{p} 62$ expression was highest in HER2-type tumors. ${ }^{17}$ These results might suggest that $\mathrm{p} 62$ overexpression is commonly seen in aggressive breast cancer subtypes. Overexpression of p62 was also observed in prostate $(91 \%)^{18}$ and digestive system cancers $(100 \%),{ }^{19}$ and the higher proportion possibly reflects site-specific variations in tumor biology.

In the present study, our data demonstrated that $\mathrm{p} 62$ overexpression favored TNBC tumors' aggressive clinical behavior, such as a higher proportion of positive lymph nodes and lymphovascular invasion, and advanced stage. Importantly, p62 overexpression was associated with a higher risk for subsequent development of distant metastases in patients with TNBC, and this was independent of clinicopathologic characteristics. Consistent with the finding from Rolland et al, it was suggested that the formation of distant metastases is significantly correlated with the degree of p62 expression. ${ }^{11}$ In addition, we also found that patients with p62 overexpression had a significantly shorter disease-free survival. Our further multivariate analysis showed that p62 overexpression was an independent predictor of short diseasefree survival of TNBC patients. Similarly, a recent report demonstrated NSCLC patients exhibiting high p62 levels have a significantly worse prognosis than patients exhibiting a low level of $\mathrm{p} 62 .{ }^{20}$ These data suggest that $\mathrm{p} 62$ overexpression is positively associated with poor prognosis.

Mechanistically, p62 is a multifunctional protein. It can regulate and modulate the activation of several signaling pathways involved in tumor formation and propagation. The second very important function of this protein is to act as a molecular adaptor between the autophagic machinery and its substrates. ${ }^{15,21}$ It is clear that the role of p62 under nonpathological conditions is to control bone and metabolic homeostasis. Bone is an important site of cancer metastasis that can be affected by cross talk between tumor and bone cells. ${ }^{15,21}$ Autophagy deficiency enhances p62 protein levels, thereby promoting tumorigenesis and tumor progression. ${ }^{22,23}$ In addition, the autophagy process reduces the genomic instability of cancer cells. This genomic instability promotes the acquisition of the secondary mutations necessary for the growth and dissemination of these cells. ${ }^{24}$ Only cells that are deficient in the autophagic pathways are able to acquire the mutations required for their growth and metastatic dissemination. $^{24,25}$

\section{Conclusion}

In summary, we have demonstrated for the first time that high levels of p62 were associated with a high biological aggressiveness of TNBC cells, because patients with p62 overexpression exhibited a higher risk of distant metastases. Similarly, patients with p62 overexpression had shorter DFS. Elucidation of the molecular mechanisms will uncover a new target molecule for anticancer therapy for TNBC patients.

\section{Acknowledgment}

This study was financially supported by the Science and Technology Program of Guangdong Province (2009B030801114). The funders had no role in study design, data collection and analysis, decision to publish, or preparation of the manuscript.

\section{Disclosure}

The authors report no conflicts of interest in this work.

\section{References}

1. Dent R, Trudeau M, Pritchard KI, et al. Triple-negative breast cancer: clinical features and patterns of recurrence. Clin Cancer Res. 2007;13: 4429-4434.

2. Carey LA, Dees EC, Sawyer L, et al. The triple negative paradox: primary tumor chemosensitivity of breast cancer subtypes. Clin Cancer Res. 2007;13:2329-2334.

3. Tischkowitz M, Brunet JS, Bégin LR, et al. Use of immunohistochemical markers can refine prognosis in triple negative breast cancer. $B M C$ Cancer. 2007;7:134. 
4. Bauer KR, Brown M, Cress RD, Parise CA, Caggiano V. Descriptive analysis of estrogen receptor (ER)-negative, progesterone receptor (PR)-negative, and HER2-negative invasive breast cancer, the so-called triple-negative phenotype: a population-based study from the California Cancer Registry. Cancer. 2007;109:1721-1728.

5. Kang Y, Siegel PM, Shu W, et al. A multigenic program mediating breast cancer metastasis to bone. Cancer Cell. 2003;3:537-549.

6. Minn AJ, Gupta GP, Siegel PM, et al. Genes that mediate breast cancer metastasis to lung. Nature. 2005;436:518-524.

7. Minn AJ, Kang Y, Serganova I, et al. Distinct organ-specific metastatic potential of individual breast cancer cells and primary. J Clin Invest. 2005;115:44-55.

8. Ciani B, Layfield R, Cavey JR, Sheppard PW, Searle MS. Structure of the ubiquitin-associated domain of p62 (SQSTM1) and implications for mutations that cause Paget's disease of bone. J Biol Chem. 2003;278: 37409-37412.

9. Seibenhener ML, Babu JR, Geetha T, Wong HC, Krishna NR, Wooten MW. Sequestosome 1/p62 is a polyubiquitin chain binding protein involved in ubiquitin proteasome degradation. Mol Cell Biol. 2004;24:8055-8068.

10. Thompson HG, Harris JW, Wold BJ, Lin F, Brody JP. p62 overexpression in breast tumors and regulation by prostate-derived Ets factor in breast cancer cells. Oncogene. 2003;22:2322-2333.

11. Rolland P, Madjd Z, Durrant L, Ellis IO, Layfield R, Spendlove I. The ubiquitin-binding protein p62 is expressed in breast cancers showing features of aggressive disease. Endocr Relat Cancer. 2007;14:73-80.

12. He J, Peng R, Yuan Z, et al. Prognostic value of androgen receptor expression in operable triple-negative breast cancer: a retrospective analysis based on a tissue microarray. Med Oncol. 2012;29:406-410.

13. Fulford LG, Easton DF, Reis-Filho JS, et al. Specific morphological features predictive for the basal phenotype in grade 3 invasive ductal carcinoma of breast. Histopathology. 2006;49:22-34.
14. Livasy CA, Karaca G, Nanda R, et al. Phenotypic evaluation of the basal-like subtype of invasive breast carcinoma. Mod Pathol. 2006;19: 264-271.

15. Moscat J, Diaz-Meco MT. p62: a versatile multitasker takes on cancer. Trends Biochem Sci. 2012;37:230-236.

16. Rodriguez A, Durán A, Selloum M, et al. Mature-onset obesity and insulin resistance in mice deficient in the signaling adapter p62. Cell Metab. 2006;3:211-222.

17. Choi J, Jung W, Koo JS. Expression of autophagy-related markers beclin-1, light chain $3 \mathrm{~A}$, light chain $3 \mathrm{~B}$ and p62 according to the molecular subtype of breast cancer. Histopathology. 2013;62:275-286.

18. Kitamura H, Torigoe T, Asanuma H, et al. Cytosolic overexpression of p62 sequestosome 1 in neoplastic prostate tissue. Histopathology. 2006;48:157-161

19. Su Y, Qian H, Zhang J, Wang S, Shi P, Peng X. The diversity expression of p62 in digestive system cancers. Clin Immunol. 2005;116: 118-123.

20. Inoue D, Suzuki T, Mitsuishi Y, et al. Accumulation of p62/SQSTM1 is associated with poor prognosis in patients with lung adenocarcinoma. Cancer Sci. 2012;103:760-766.

21. Bjørkøy G, Lamark T, Brech A, et al. p62/SQSTM1 forms protein aggregates degraded by autophagy and has a protective effect on huntingtin-induced cell death. J Cell Biol. 2005;171:603-614.

22. Mathew R, Karp CM, Beaudoin B, et al. Autophagy suppresses tumorigenesis through elimination of p62. Cell. 2009;137:1062-1075.

23. Takamura A, Komatsu M, Hara T, et al. Autophagy-deficient mice develop multiple liver tumors. Genes Dev. 2011;25:795-800.

24. Mathew R, Kongara S, Beaudoin B, et al. Autophagy suppresses tumor progression by limiting chromosomal instability. Genes Dev. 2007;21:1367-1381.

25. Mathew R, Karantza-Wadsworth V, White E. Role of autophagy in cancer. Nat Rev Cancer. 2007;7:961-967.
OncoTargets and Therapy

\section{Publish your work in this journal}

OncoTargets and Therapy is an international, peer-reviewed, open access journal focusing on the pathological basis of all cancers, potential targets for therapy and treatment protocols employed to improve the management of cancer patients. The journal also focuses on the impact of management programs and new therapeutic agents and protocols on

\section{Dovepress}

patient perspectives such as quality of life, adherence and satisfaction The manuscript management system is completely online and includes a very quick and fair peer-review system, which is all easy to use. Visit http://www.dovepress.com/testimonials.php to read real quotes from published authors. 